\title{
Penetrating renal injuries: an observational study of non operative management and the impact of opening Gerota's fascia
}

Thomas West Clements

University of Calgary

Chad Geoffrey Ball

University of Calgary

Andrew J Nicol

University of Cape Town

Sorin Edu

University of Cape Town

Andrew W Kirkpatrick

University of Calgary

Pradeep Navsaria ( $\sim$ pradeep.navsaria@uct.ac.za )

University of Cape Town

\section{Research Article}

Keywords: Penetrating Solid Organ Injury, Renal Trauma, Non-Operative Management

Posted Date: February 4th, 2022

DOI: https://doi.org/10.21203/rs.3.rs-1315851/v1

License: (c) (i) This work is licensed under a Creative Commons Attribution 4.0 International License.

Read Full License 


\section{Abstract}

Background: Non-operative management has become increasingly popular in the treatment of renal trauma. While data is robust in blunt mechanisms, the role of non-operative management in penetrating trauma is less clear. Additionally, there is a paucity of data comparing gunshot and stab wounds.

Methods: A retrospective review of patients admitted to a high-volume level 1 trauma center (Groote Schuur Hospital, Cape Town) with penetrating abdominal trauma was performed. Patients with renal injuries were identified and compared based on mechanism (gunshot (GSW) versus stab) and management strategy (operative vs non operative). Primary outcomes of interest were mortality and failure of non-operative management. Secondary outcomes of interest were nephrectomy rates, ClavienDindo complication rate, hospital length of stay, and overall morbidity rate.

Results: A total of 150 patients with renal injuries were identified (82 GSW, 68 stab). Overall, $55.2 \%$ of patients required emergent/urgent laparotomy. GSWs were more likely to cause grade $V$ injury and concurrent intra-abdominal injuries ( $p>0.05)$. The success rate of non-operative management was $91.6 \%$ (89.9\% GSW, $92.8 \%$ stab, $p=0.64)$. The absence of hematuria on point of care testing demonstrated a negative predictive value of $98.4 \%$ (95\% $\mathrm{Cl}=96.8 \%-99.2 \%)$. All but 1 patient who failed non-operative management had associated intra-abdominal injuries requiring surgical intervention. Opening of Gerota's fascia resulted in nephrectomy in $55.6 \%$ of cases. There were no statistically significant risk factors for failure of non-operative management identified on univariate logistic regression.

Conclusions: NOM of penetrating renal injuries can be safely and effectively instituted in both gunshot and stab wounds with a very low number of patients progressing to laparotomy. Most patients fail NOM for associated injuries. During laparotomy, the opening of Gerota's fascia may lead to increased risk of nephrectomy. Ongoing study with larger populations is required to develop effective predictive models of patients who will fail NOM.

\section{Background}

Penetrating abdominal trauma has undergone a massive shift in recent decades. The historical experience of mandatory laparotomies has been supplanted by selective non-operative management (NOM) based on clinical risk factors and advanced diagnostic imaging ${ }^{1-7}$. While blunt renal trauma has long been managed conservatively with fantastic results, conservative management of penetrating trauma to the kidney has only more recently been explored ${ }^{8-14}$. The candidacy for non-operative management, as well as the risk factors for failure, remain poorly defined ${ }^{7,13,14}$. Additionally, differences in penetrating mechanisms (gunshot vs stab), have yet to be studied extensively.

Large, multi-centered experience has shown that grade of injury and concomitant abdominal injury are risk factors for failure of non-operative management in penetrating renal trauma ${ }^{8,10}$. Once in the operating theatre, the risk that these patients undergo radical nephrectomy is not insignificant ${ }^{15}$. 
Increased understanding of the patient population who may be managed without intervention represents an opportunity to preserve patient renal function, decrease dialysis rates, and minimize the overall clinical burden of traumatic renal injuries. The clinical course of patient undergoing NOM, especially those

sustaining gunshot wounds (GSW), is becoming increasingly well defined ${ }^{16-19}$. However, an in depth understanding of the differences in patients who fail, and more specifically why they fail, is elusive.

While blunt renal injuries predominate the North American trauma literature, penetrating trauma happens with greater incidence in many low- and middle-income countries ${ }^{12}$. In these settings, cross sectional imaging is less common-place and the clinical exam is paramount. This manuscript reports the largest single center experience with penetrating renal trauma to date. This retrospective data serves to further delineate patients who may or may not require operative management of penetrating renal injuries. Additionally, a comparison between stab and gunshot wounds is made.

\section{Methods}

\section{Database Design}

The Groote-Schuur Hospital (GSH) in Cape Town, South Africa is a high-volume level 1 trauma center which prospectively maintains a database of all patients presenting with penetrating abdominal trauma. All patients are included regardless of age or ISS. Patients who die in the trauma bay prior to admission to the ward are not included. Patients sustaining major thoracic, cardiac, or neurosurgical trauma are also excluded. Database metrics include presenting demographics, comorbidities, vitals, injury severity, diagnostic testing, and procedures/interventions. Outcomes recorded include length of hospital/ICU stay, complications, disposition, and mortality data.

\section{Patient Population}

All patients presenting to GSH with isolated, penetrating, abdominal trauma from April $30^{\text {th }}, 2015$ to January $30^{\text {th }}, 2019$ were retrospectively reviewed. Patients diagnosed with any grade of renal trauma through operative or computed tomography (CT) findings were included. All patients suffering stab or gunshot wounds were included. Patients sustaining combined penetrating and blunt mechanisms were excluded. Patients were analyzed as a whole, as well as in stab vs gunshot wound subgroups. Patients who did not undergo immediate, urgent laparotomy after their initial assessment were classified as having undergone "Non-operative Management" (NOM). Patients undergoing delayed laparotomy after admission for NOM were analyzed in an intention to treat fashion as part of the NOM group. Patients taken urgently to the operating theatre on admission for any reason were deemed "Operative Management" (OM). All patients were included regardless of injury severity or outcomes. Morbidity was graded based on the Clavien-Dindo classification system. Patient files were reviewed by 2 independent reviewers.

\section{Analysis}


Primary outcomes of interest included failure of NOM, mortality, and complications rates. Secondary outcomes included hospital LOS, ICU LOS, and rates of renal failure. All statistics were done using commercially available SPSS ${ }^{\circledR}$ software. Categorical variables were analyzed using chi-squared, or Fischer's exact test where appropriate. Means of continuous variables were compared using the students T-test. Medians were compared using Mann-U-Whitney testing. Univariate logistic regressions were employed to identify factors contributing to failure of NOM. Standard statistical methodology was employed ( $p<0.05=$ significant).

\section{Results}

A total of 899 patients were admitted with penetrating abdominal trauma (GSW=563, Stab=336). 150 patients were diagnosed with a penetrating renal injury (GSW=54.7\%, Stab $=45.3 \%)$. Isolated renal trauma was encountered in 50 patients (33.3\%). Concurrently injured organs were most commonly the liver (40.7\%), diaphragm (25.3\%), and colon (24.0\%). No resuscitative thoracotomies were performed in either group. Patients sustaining GSW's were more severely injured, more often presented with peritonitis, had a higher rate of concurrent injury, and more often had unstable vitals $(p<0.05)$. Demographic and vitals information is demonstrated in Table 1.

\section{Initial Investigations}

Of all patients ( $\mathrm{n}=899)$ admitted with penetrating abdominal trauma, $110(12.2 \%, 95 \% \mathrm{Cl}=10.2-14.6)$ were reported to have gross hematuria ( $\mathrm{stab}=26.4 \%(95 \% \mathrm{Cl}=18.4-35.6 \%), \mathrm{GSW}=73.6 \%(95 \% \mathrm{Cl}=64.4-81.6 \%)$ ), $42.7 \%(95 \% \mathrm{Cl}=33.3-52.5 \%)$ ) of which did not have a renal injury. Microhematuria was observed in 332 patients $(\mathrm{Stab}=38.6 \%(95 \% \mathrm{Cl}=33.3-44.0 \%), \mathrm{GSW}=58.4 \%(95 \% \mathrm{Cl}=52.9-63.8 \%)), 244(73.5 \%)$ of which did not have a renal injury. Overall, any form of hematuria had a $95.3 \%$ sensitivity $(95 \% \mathrm{Cl}=90.5 \%-98.1 \%)$ and $60.3 \%(95 \% \mathrm{Cl}=56.7 \%-63.9 \%)$ specificity for renal injury, with a negative predictive value of $98.4 \%$ (95\% $\mathrm{Cl}=96.8 \%-99.2 \%)$. Of patients with kidney injuries who required immediate laparotomy, $94.0 \%$ $(95 \% \mathrm{Cl}=90.5-98.1 \%)$ had hematuria, $44.7 \%(95 \% \mathrm{Cl}=36.3-53.3 \%)$ of which was gross hematuria. The negative predictive value of clear urine (no gross or microscopic hematuria) for ruling out a renal injury in a patient requiring immediate laparotomy for any reason was $98.7 \%(95 \% \mathrm{Cl}=96.3 \%-99.6 \%)$.

Of all patients, 496 (55.2\%) underwent urgent laparotomy. Immediate laparotomy based on clinical exam alone was performed in 351 patients (70.5\%). An immediate laparotomy following admission CT scan was performed in 145 patients (34.0\%). Urgent CT scan at the time of admission was deemed appropriate in 426 patients (47.4\%).

Of patients with a renal injury ( $n=150), 73.3 \%$ had an urgent CT scan. Renal injury was diagnosed at the time of emergent laparotomy without CT scan in 40 patients $(26.7 \%)$. The most common indication for laparotomy in patients with renal injuries was peritonitis (67.8\%), followed by radiographic findings at CT scan (18.5\%), and hemodynamic instability (12.3\%). Of patients with renal injuries taken for emergent laparotomy, $84.6 \%$ had sustained gunshot wounds. 
AAST grading of renal injuries found on CT scan or intraoperatively are demonstrated in Table 2. The most common injuries were grade III (39.3\%), and Grade IV (30.0\%). Gross hematuria was not associated with higher AAST grade kidney injuries (Grade IV/V) $(p=0.22)$.

\section{Operative Management}

Management decisions and outcomes are found in Figures 1 through 3. Overall, 55.3\% of all patients with kidney injuries were managed non-operatively. Non-operative management was successful in $91.6 \%$ of cases. Patients with gunshot wounds were taken to the OR much more commonly than patients with stab wounds (67.1\% vs $14.7 \%$ ) ( $p$-value<0.001). Gunshot wounds were much more likely to cause AAST grade $V$ injuries ( $p=0.0001)$, which in turn were far more likely to be managed operatively compared to all other grades $(92.8 \%$ vs $39.7 \%, p<0.001)$. In patients with isolated renal trauma $(n=50)$, only $4(8.0 \%)$ required laparotomy, all for open kidney repair, none of which required nephrectomy. In all patients going to the OR who underwent total or partial nephrectomy, $100.0 \%$ required additional surgical intervention. Of these, $95.7 \%$ required major visceral repair/resection, or damage control surgery. The remaining patient required simple liver packing for an AAST Grade II liver injury and was closed primarily. Patients with isolated renal trauma were caused by stab wounds $90 \%$ of the time. Patients with gunshot wounds to the abdomen that cause renal injuries were far more likely to have concurrent intrabdominal injuries (93.9\% vs 33.8\%, $\mathrm{p}<0.01)$. The overall rate of nephrectomy for all patients (OM and NOM) was $13.3 \%(95 \% \mathrm{Cl}=8.3-19.8 \%)$. Nephrectomy was far more common in GSW than stab wounds ( $23.1 \%$ vs $1.5 \%$, p-value $<0.0001)$. Other interventions included partial nephrectomy $(2.0 \%)$, primary repair $(2.0 \%)$, and "other" procedures (exploration only, hemorrhage control with electrocautery, and simple packing) (6.7\%). For patients in whom Gerota's fascia was opened, total nephrectomy was the most common procedure at a rate of $55.6 \%(95 \% \mathrm{Cl}=38.7 \%-72.3 \%, \mathrm{p}<0.001)$, partial nephrectomy occurred in $8.3 \%(95 \% \mathrm{Cl}=0.0-17.7 \%)$, open repair in $8.3 \%(95 \% \mathrm{Cl}=0.0-17.7 \%)$, and "other" procedures (packing, simple exploration, application of energy devices/hemostatics) in $27.8 \%$ (95\% $\mathrm{Cl}=12.6-42.9 \%)$. Patients undergoing total nephrectomy (20), were more likely to have grade IV $(8,40 \%)$, or $\mathrm{V}(12,60 \%)$ injuries $(\mathrm{p}<0.001)$. All patients undergoing partial nephrectomy (3) had AAST grade IV injuries. Primary repair was performed in 1 patient with a grade IV injury, and 2 patients with grade III injuries. Hemorrhage control, exploration, or simple packing were performed in 3 grade IV, 3 grade III, 3 grade II, and 1 grade I injury.

\section{Non-Operative Management}

Non-operative management was successful in $91.6 \%$ of cases. Rates of success of NOM were not different between GSW and stab groups ( $89.9 \%$ vs. $92.8 \%$, p-value $=0.64)$. Univariate logistic regression for factors predicting failure of non-operative management is found in Table 3. None of the recorded variables were reliable predictors of NOM failure on univariate analysis, and therefore multivariate analysis was not performed. In patients undergoing NOM, 5(6.0\%) required angioembolization (4 kidney, 1 liver). A total of $4(4.8 \%)$ patients required percutaneous drainage of collections, all due to abscess or biloma from concurrent liver injuries. A single patient re-presented with frank hematuria after discharge with no findings on repeat CT angiogram and spontaneous resolution. No patient required cystoscopy or 
nephrostomy. Of the 7 (8.4\%) patients failing NOM, only 1 required nephrectomy. This patient additionally required damage control for deterioration of a severe liver injury. A single patient underwent an exploration of the kidney only. The remainder failed due to hollow viscous injury (2), hemorrhage from the spleen (1), wound sepsis requiring debridement (1), and concern for ongoing liver hemorrhage (1).

Comparisons of NOM and OM are found in Table 4. Compared to patients undergoing operative management, patients undergoing NOM had lower mortality rates, hospital length of stay, and complication rates, but were also less severely injured. In patients who were management non-operatively, there were no differences in patients sustaining GSW vs stab wounds with regards to mortality ( 0.0 vs $0.0 \%, p=1.0)$, overall complication rate $(18.5 \%$ vs $12.5 \%$, $p$-value $=0.53)$, Clavien-Dindo III/IV complication rate $(11.1 \%$ vs $7.1 \%$, $p$-value $=0.54)$, or readmission rate $(7.4 \%$ vs. $8.9 \%$, $p$-value $=0.90)$. The median length of stay was longer in GSW victims managed non-operatively vs stab victims (5.0 vs $3.0, p=0.018$ ). Comparisons of GSW and stab outcomes are found in Table 5.

\section{Discussion}

Much work has been done in the last two decades to delineate trauma populations benefiting from restraint on the part of the trauma surgeon ${ }^{5,8,9}$. Advancements in percutaneous therapies have also revolutionized the management of solid organ injuries. As a retroperitoneal structure, the kidney is theoretically a prime candidate for NOM. The body's ability to tamponade the retroperitoneum, along with the ease of embolization and/or minimally invasive urologic interventions would predict that a number of kidney injuries can be managed without immediate surgical intervention. In contrast to blunt trauma in which parenchymal injury dominates, missile trajectories in penetrating trauma seemingly could introduce a higher likelihood of injury to the larger vascular and calyceal structure ${ }^{5-8,10}$. Perhaps unsurprisingly, the NOM of penetrating renal injuries has therefore lagged behind. Furthermore, most studies have grouped stab and gunshot wounds into a single group $8,10,11,13.14$. Differences in the outcomes in NOM of gunshot vs stab wounds, is relatively sparse. Delineating the mechanism and frequency of failure of NOM allows for improved management of the pathology.

Overall, NOM was safe and effective with appropriate selection. With a mortality rate of $0.0 \%$ and a success rate of $91.6 \%$, the safety profile of NOM was excellent. Patients requiring immediate laparotomies almost always require operation due to associated injuries, regardless of the grade of renal insult. This is echoed in NOM, where the majority of failures are due to concomitant injuries. Only 1 patient who failed NOM actually required a nephrectomy. If requirement for renal intervention only is taken as the criteria for failure, NOM is successful in $97.6 \%$ of cases. Furthermore, NOM was safe in both gunshot and stab wounds with appropriate selection, with no statistical difference in outcomes or failure rates between the two mechanisms. While fewer patients are candidates, the NOM of renal gunshot wounds has an equivalent success rate to stab wounds.

Patients were rarely taken to the operating room for intervention on the kidney alone. In both up-front OM, and failed NOM, indications for laparotomy were almost always present independent of the renal injury. 
Regardless, if Gerota's fascia was opened intraoperatively, more than half of these patients had their kidney removed. This study and many others show that even high-grade injuries can be managed nonoperatively, regardless of grade ${ }^{1,3,5}$. Additionally, there were patients in this dataset with grade $\mathrm{V}$ renal injuries who underwent laparotomy in whom renal salvage was attained by not violating Gerota's fascia. While there are many clinical scenario's which require expeditious nephrectomy, the exploration of Gerota's fascia alone dramatically increases the chances of renal loss. The decision to explore the kidney should therefore be made thoughtfully in light of the overwhelming success of NOM.

The most pressing question in NOM is patient selection. At GSH, the standard indications of peritonitis, hemodynamic instability, and bowel evisceration are used to select patients for up front-operative management. Examinable patients lacking the above indications will then undergo CT scanning based on clinical exam, hematuria results, and missile tract. Patients meeting the above criteria can almost always be reliably treated non-operatively. Patients without hematuria do not routinely undergo CT scanning in the absence of a concerning missile tract on physical exam. The concept that NOM is safe may be helpful in setting where resources may be scarce, or unreliably available.

This study has multiple limitations. The retrospective nature of the study creates the possibility of reporting bias. Additionally, the granular aspects of surgical management of the injured kidney are difficult to elucidate, as are the reasons for failure of NOM in cases of multiple abdominal or missed injuries. The power of the study is likely a limitation in the determination of significant predictors for failure. AAST grade and acidosis have been previously identified as risk factors for nephrectomy 8,10 , neither of which was borne out in this study. As these outcomes are rare in NOM, the study was likely not powered to detect these risk factors.

This data demonstrates that NOM can be equally effective in gunshot and stab wounds when patient selection is appropriate. Nephrectomy is a rare occurrence, and complication rates are relatively low. Additionally, patients undergoing NOM most often fail due to associated injuries to other abdominal organs, as opposed to the kidney itself. The effective selection of patients for NOM has the potential to decrease unnecessary nephrectomies, decrease resource utilization, and overall improve patient outcomes.

\section{Conclusion}

NOM of penetrating renal injuries can be safely and effectively instituted in both gunshot and stab wounds with a very low number of patients progressing to laparotomy. Most patients fail NOM for associated injuries. During laparotomy, the opening of Gerota's fascia may lead to decompression of controlled hemorrhage, and subsequent risk of nephrectomy. Ongoing study with larger population is required to develop effective predictive models of patients who will fail NOM.

\section{Abbreviations}


AAST: American association for the surgery of trauma

CT: Computed tomography

GSH: Groote Schuur Hospital

GSW: Gunshot wound

ICU: Intensive care unit

ISS: Injury Severity Score

LOS: Length of stay

NOM: Non-operative management

OM: Operative management

\section{Declarations}

Ethics approval: Ethics review for this study was provided by the institutional review board of the University of Cape Town

Availability of data and materials: The datasets generated and/or analysed during the current study are not publicly available due to patient privacy restrictions, but are available from the correspond author on reasonable request.

Funding: Not applicable. No sources of funding are declared.

Consent for publication: Not applicable

Competing interests: AW Kirkpatrick has consulted for the Zoll, Acelity $(3 \mathrm{M} / \mathrm{KCl}), \mathrm{CSL}$ Behring, Innovative Trauma Care and SAM Medical Corporations, and the Statesman Group of Companies, and is the PI of a randomized trial partially supported by the Acelity Corporation.

Authors contributions: TWC and PN were involved in all aspects of the manuscript. AJN, SE were involved in the collection and analysis of data, writing, review, and approval of the final manuscript. CB and AWK were involved in analysis, writing, review, and approval of the final manuscript.

\section{References}

1. Demetriades D, Hadjizacharia P, Constantinou C, Brown C, Inaba K, Rhee P, Salim A. "Selective Nonoperative Management of Penetrating Abdominal Solid Organ Injuries". Ann Surg. 2006;244(4):620-628. 
2. Navsaria P, Nicol A, Krige J, Edu S, Chowdhury S. "Selective nonoperative management of liver gunshot injuries”. Eur J Trauma Emerg Surg. 2019;45(2):323-328.

3. Navsaria PH, Nicol AJ, Edu S, Gandhi R, Ball CG. "Selective nonoperative management in 1106 patients with abdominal gunshot wounds: conclusions on safety, efficacy, and the role of selective CT imaging in a prospective single-center study". Ann Surg. 2015;261(4):760-764.

4. Navsaria PH, Nicol AJ, Krige JE, Edu S. "Selective nonoperative management of liver gunshot injuries". Ann Surg. 2009;249(4):653-656.

5. Navsaria PH, Nicol AJ. "Selective nonoperative management of kidney gunshot injuries". World J Surg. 2009;33(3):553-557.

6. Rawahi AA, Hinai FA, Boyd JM, Doig CJ, Ball CG, Velmahos GC, Kirkpatrick AW, Navsaria PH, Roberts DJ. "Outcomes of selective nonoperative management of civilian abdominal gunshot wounds: A systematic review and meta-analysis" World J Emerg Surg. 2018;13:55.

7. Lamb CW, Garner JP. "Selective non-operative management of civilian gunshot wounds to the abdomen: A systematic review of the evidence" Injury. 2014;45(4):659-666.

8. Bjurlin MA, Fantus RJ, Fantus RJ, Villines D. "Comparison of nonoperative and surgical management of renal trauma: Can we predict when nonoperative management fails?". J Trauma. 2017;82(2):356361.

9. du Plessis WE, du Plessis DE, Bruce JL, Smith MT, Clarke DL. "High grade renal trauma: Does the mechanism of penetrating injury influence renal salvage rate?". Injury. 2021;Doi:S00201383(21)00694.

10. Kuan JK, Wright JL, Nathens AB, Rivara FP, Wessells H. "American Association for the Surgery of Trauma Organ Injury Scale for kidney injuries predicts nephrectomy, dialysis, and death in patients with blunt injury and nephrectomy for penetrating injuries". J Trauma. 2006;60(2):351-356

11. Majed W. El Hechi, Charlie Nederpelt, Napaporn Kongkaewpaisan, Alexander Bonde, Nikolaos Kokoroskos, Kerry Breen, Ahmed Nasser, Noelle N. Saillant, Haytham M.A. Kaafarani, George C. Velmahos, April E. Mendoza. "Contemporary management of penetrating renal trauma - A national analysis" Injury. 2020;51(1):32-38.

12. Salem MS, Urry RJ, Kong VY, Clarke DL, Bruce J, Laing GL. "Traumatic renal injury: Five-year experience at a major trauma centre in South Africa". Injury. 2020;51(1):39-44.

13. Resch TR, Kufera JA, Chiu W, Scalea TM. "Penetrating Renal Trauma: Nonoperative Management is Safe in Selected Patients". Am Surg. 2019;85(3):266-272.

14. Salem MS, Urry RJ, Kong VY, Clarke DL, Bruce J, Laing GL. "Traumatic renal injury: Five-year experience at a major trauma centre in South Africa". Injury. 2020;51(1):39-44.

15. Keihani S, Xu Y, Presson AP, Hotaling JM, Nirula R, Piotrowski J et al.. "Contemporary management of high-grade renal trauma: Results from the American Association for the Surgery of Trauma Genitourinary Trauma Study". J Trauma Acute Care Surg. 2018;84(3):418-425.

16. Schellenberg M, Benjamin E, Piccinini A, Inaba K, Demetriades D. "Selective nonoperative management of renal gunshot wounds”. J Trauma Acute Care Surg. 2019;87(6):1301-1307. 
17. Moolman C, Navsaria PH, Lazarus J, Pontin A, Nicol AJ. “Nonoperative management of penetrating kidney injuries: a prospective audit”. J Urol. 2012;188(1):169-173.

18. Oosthuizen GV, Weale R, Kong VY, Bruce JL, Urry RJ, Laing GL, Clarke DL. "The effect of a concomitant renal injury on the outcome of colonic trauma". Am J Surg. 2018;216(2):230-234.

19. Nicol AJ, Theunissen D. "Renal salvage in penetrating kidney injuries: a prospective analysis" J Trauma. 2002;53(2):531-353.

\section{Tables}

Table 1: Presenting clinical and demographic data from patients admitted to GSH with penetrating renal injuries from April $30^{\text {th }}, 2015$ to January $30^{\text {th }}, 2019$. $Y=y e a r s, ~ I Q R=I n t e r q u a r t i l e ~ R a n g e, ~ S B P=S y s t o l i c$ Blood Pressure, ISS=Injury Severity Score, $\mathrm{Hb}=$ Hemoglobin, GSW=Gunshot wound. Hemodynamic instability is defined as a SBP $<90 \mathrm{mmHG}$, or $\mathrm{HR}>100$ beats per minute.

\begin{tabular}{|c|c|c|c|c|}
\hline & $\begin{array}{l}\text { Overall } \\
(\mathrm{N}=150)\end{array}$ & GSW (N=82) & $\begin{array}{l}\text { Stab } \\
(\mathrm{N}=68)\end{array}$ & $\begin{array}{l}\mathrm{p}- \\
\text { value }\end{array}$ \\
\hline Median Age (y)(IQR) & $\begin{array}{l}25.5(\mathrm{IQR}=21- \\
31)\end{array}$ & $\begin{array}{l}26.5(\mathrm{IQR}=21- \\
31.5)\end{array}$ & $25.0(\mathrm{IQR}=22-31)$ & 0.56 \\
\hline$\%$ Male & $95.3 \%$ & $93.9 \%$ & $97.1 \%$ & 0.36 \\
\hline Median \# of Wounds & $2(\mathrm{IQR}=1-4)$ & $2(\mathrm{IQR}=1-4)$ & $2(\mathrm{IQR}=1-4)$ & 0.56 \\
\hline HIV Status(\% positive) & $5.3 \%$ & $7.3 \%$ & $2.9 \%$ & 0.23 \\
\hline $\begin{array}{l}\text { Mean Presenting HR }(\mathrm{bpm} \pm 95 \% \\
\mathrm{Cl})\end{array}$ & $91.4 \pm 3.7$ & $95.6 \pm 5.2$ & $86.2 \pm 3.2$ & 0.01 \\
\hline $\begin{array}{l}\text { Mean presenting SBP } \\
(\mathrm{mmHg} \pm 95 \% \mathrm{Cl}\end{array}$ & $128.6 \pm 3.9$ & $129.0 \pm 6.0$ & $128.2 \pm 4.7$ & 0.41 \\
\hline Mean ISS & $21.3 \pm 2.7$ & $28.2 \pm 4.2$ & $13.2 \pm 1.7$ & $<0.05$ \\
\hline Presenting $\mathrm{pH}$ & $7.33 \pm 0.02$ & $7.32 \pm 0.03$ & $7.33 \pm 0.02$ & 0.30 \\
\hline Initial Lactate & $2.8 \pm 0.5$ & $3.1 \pm 0.6$ & $2.5 \pm 0.9$ & 0.26 \\
\hline Presenting $\mathrm{Hb}$ & $126.2 \pm 2.0$ & $130.0 \pm 2.6$ & $115.0 \pm 1.3$ & 0.78 \\
\hline Peritonitis(\%) & 36.7 & 58.5 & 10.2 & $<0.05$ \\
\hline Hemodynamic Instability(\%) & 6.0 & 8.5 & 2.9 & 0.15 \\
\hline Isolated Renal Injury (\%) & 33.3 & 6.1 & 66.2 & $<0.05$ \\
\hline
\end{tabular}

Table 2: American Association for the Surgery of Trauma(AAST) grade of renal injuries in patients with penetrating stab and gunshot wounds(GSW) admitted to GSH during the study period. 


\begin{tabular}{|llll|}
\hline AAST Grade & Stab $(n=68)$ & GSW $(n=82)$ & p-value \\
\hline I & 2 & 3 & 1.0 \\
\hline II & 16 & 11 & 0.15 \\
\hline IV & 26 & 33 & 0.06 \\
\hline V & 24 & 21 & 0.19 \\
\hline
\end{tabular}

Table 3: Univariate logistic regression for factors predictive of failure in NOM.

\begin{tabular}{|lll|}
\hline Characteristic & Univariate Logistic Regression p-value \\
\hline Age & & \\
GSW & & 1.0 \\
AAST Grade & I & 1.0 \\
& II & 0.532 \\
& III & 0.774 \\
& IV & 0.714 \\
\cline { 2 - 3 } & V & - \\
& (III-V) & 0.55 \\
High Grade Injury & 1.0 \\
\hline SBP<90 & & 0.53 \\
\hline HR>100 & 0.94 \\
\hline ISS & 0.87 \\
\hline Lactate & 0.65 \\
\hline Gross Hematuria & 0.11 \\
\hline pH & & \\
\hline
\end{tabular}

SBP = Systolic Blood Pressure, HR = Heart Rate, ISS=injury severity score, AAST=American Association for the Surgery of Trauma, GSW=Gunshot Wound. High grade injuries were defined as AAST grade III, IV, and $\mathrm{V}$ injuries.

Table 4: Comparisons of outcomes in non-operative management(NOM) and operative management (OM) for patients with penetrating renal trauma. LOS= Length of Stay 


\begin{tabular}{|lllll|}
\hline Outcome Measure & Overall $(\mathrm{n}=150)$ & $\mathrm{NOM}(\mathrm{n}=83)$ & $\mathrm{OM}(\mathrm{n}=67)$ & $\mathrm{p}$-value \\
\hline Mortality & $7.3 \%$ & $1.2 \%$ & $14.9 \%$ & 0.001 \\
\hline Median Length of Stay (days) & 5.0 & 4.0 & 8.5 & $<0.001$ \\
\hline Mean ICU LOS (days) & 4.1 & 6.0 & 3.9 & 0.14 \\
\hline Mean Ventilated Days(days) & 3.2 & 2.0 & 3.3 & 0.29 \\
\hline Overall Complication Rate & $35.3 \%$ & $14.4 \%$ & $61.2 \%$ & $<0.001$ \\
\hline Clavien-Dindo III/IV complication rate & $19.3 \%$ & $8.4 \%$ & $32.8 \%$ & $<0.001$ \\
\hline Readmission Rate & $9.3 \%$ & $8.4 \%$ & $10.4 \%$ & 0.67 \\
\hline
\end{tabular}

Table 5: Subgroup analysis of stab wounds and gunshot wounds managed by non-operative management.

\begin{tabular}{|c|c|c|c|c|c|c|c|}
\hline \multirow[t]{2}{*}{ Outcome Measure } & \multicolumn{3}{|c|}{ Stab $(n=68)$} & \multicolumn{3}{|c|}{$\operatorname{GSW}(n=82)$} & \multirow{2}{*}{$\begin{array}{l}\text { NOM of Stab vs } \\
\text { GSW } \\
\text { p-value }\end{array}$} \\
\hline & $\begin{array}{l}\text { OM } \\
\text { (12) }\end{array}$ & $\begin{array}{l}\text { NOM } \\
\text { (56) }\end{array}$ & $\begin{array}{l}\mathrm{p}- \\
\text { value }\end{array}$ & $\mathrm{OM}(55)$ & $\begin{array}{l}\text { NOM } \\
\text { (27) }\end{array}$ & $\begin{array}{l}\mathrm{p}- \\
\text { value }\end{array}$ & \\
\hline Mortality(\%) & 8.3 & 0.0 & 0.17 & 16.4 & 0.0 & 0.026 & 1.0 \\
\hline Median LOS(days) & 5.0 & 3.0 & 0.045 & 9.0 & 5.0 & 0.046 & 0.018 \\
\hline Mean ICU LOS(days) & 3.0 & 1.0 & - & 4.0 & 12.0 & - & - \\
\hline $\begin{array}{l}\text { Mean Ventilated Days } \\
\text { (days) }\end{array}$ & 2.0 & 0.0 & - & 3.4 & 2 & - & - \\
\hline Overall Complication(\%) & 50.0 & 12.5 & 0.003 & 63.6 & 18.5 & 0.0001 & 0.53 \\
\hline Clavien-Dindo III/IV(\%) & 25.0 & 7.1 & 0.10 & 34.5 & 11.1 & 0.033 & 0.54 \\
\hline Readmission Rate(\%) & 16.7 & 8.9 & 0.60 & 9.1 & 7.4 & 0.80 & 0.90 \\
\hline
\end{tabular}

LOS = Length of stay, GSW = Gunshot wound, OM=Operative Management, NOM=Non-operative Management.

\section{Figures}




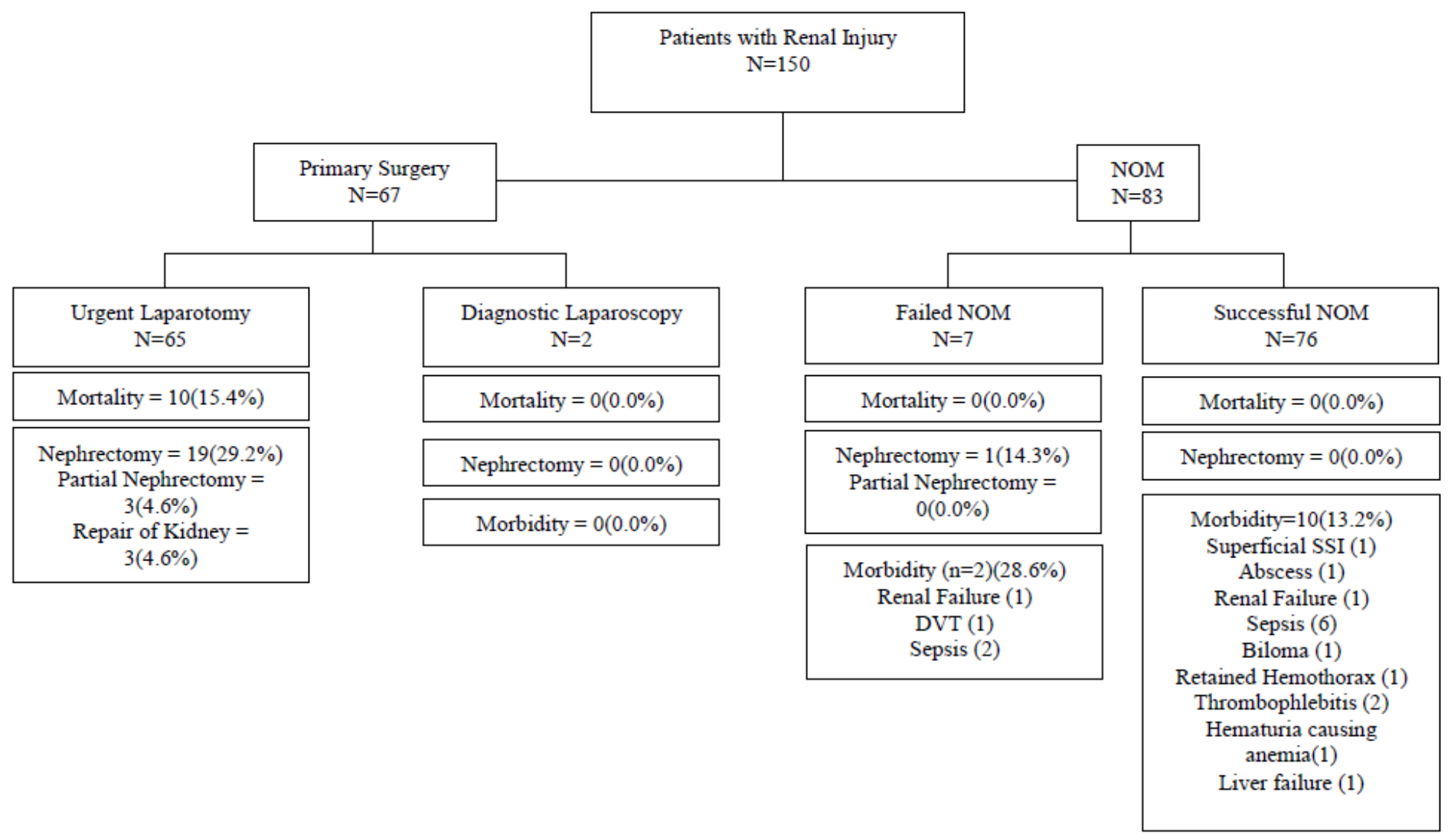

\section{Figure 1}

Clinical decision pathways and outcomes for all patients with renal injuries. NOM = Non-operative management. Failure of NOM was defined as a need for any abdominal surgical intervention. Successful NOM patients were managed without the need for surgical intervention. All patients in diagnostic laparoscopy group were planned, delayed operations for left sided thoracoabdominal stab wounds. DVT= Deep Vein Thrombosis 


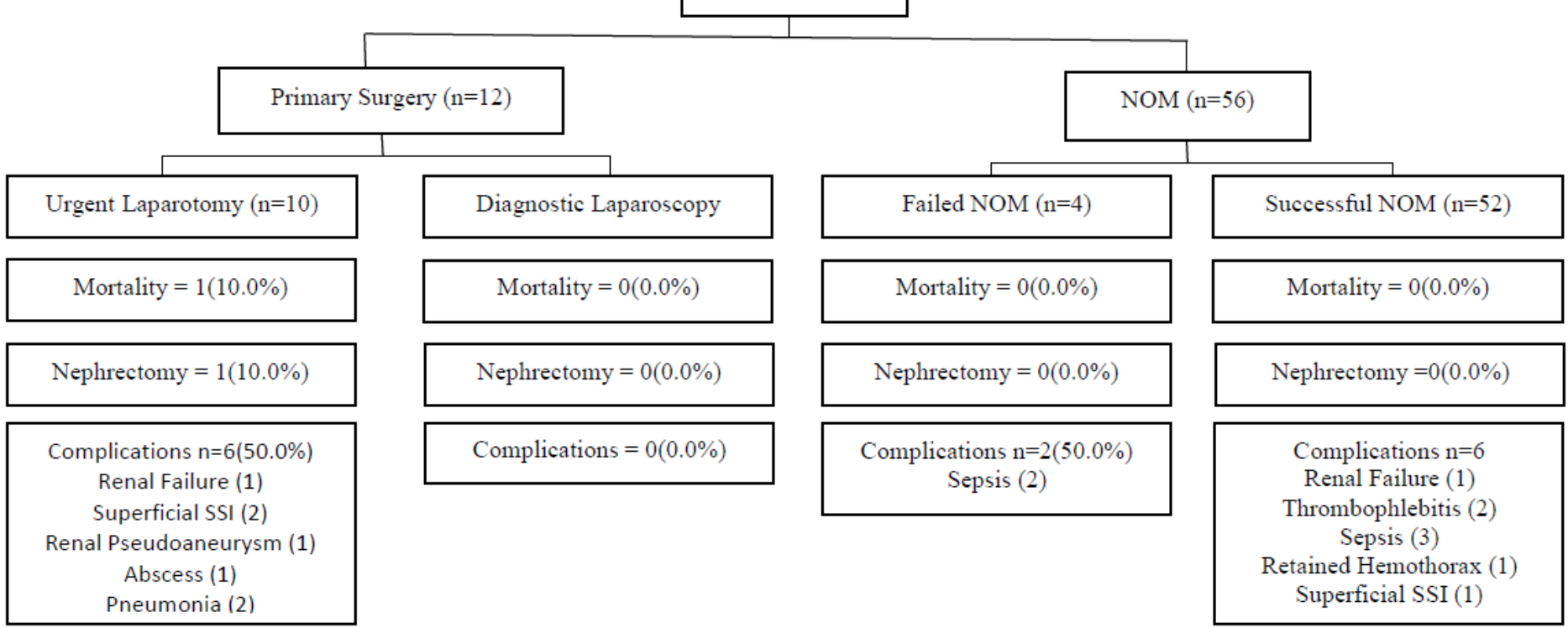

\section{Figure 2}

Clinical decision pathways and outcomes for patients sustaining abdominal stab wounds causing renal injuries. NOM = Non-operative management. Failure of NOM was defined as a need for laparotomy. Successful NOM patients were managed without the need for surgical intervention. Primary surgery is defined as the need for emergent/urgent laparotomy directly from the emergency department prior to admission to a hospital ward/intensive care unit. SSI = Surgical Site Infection 


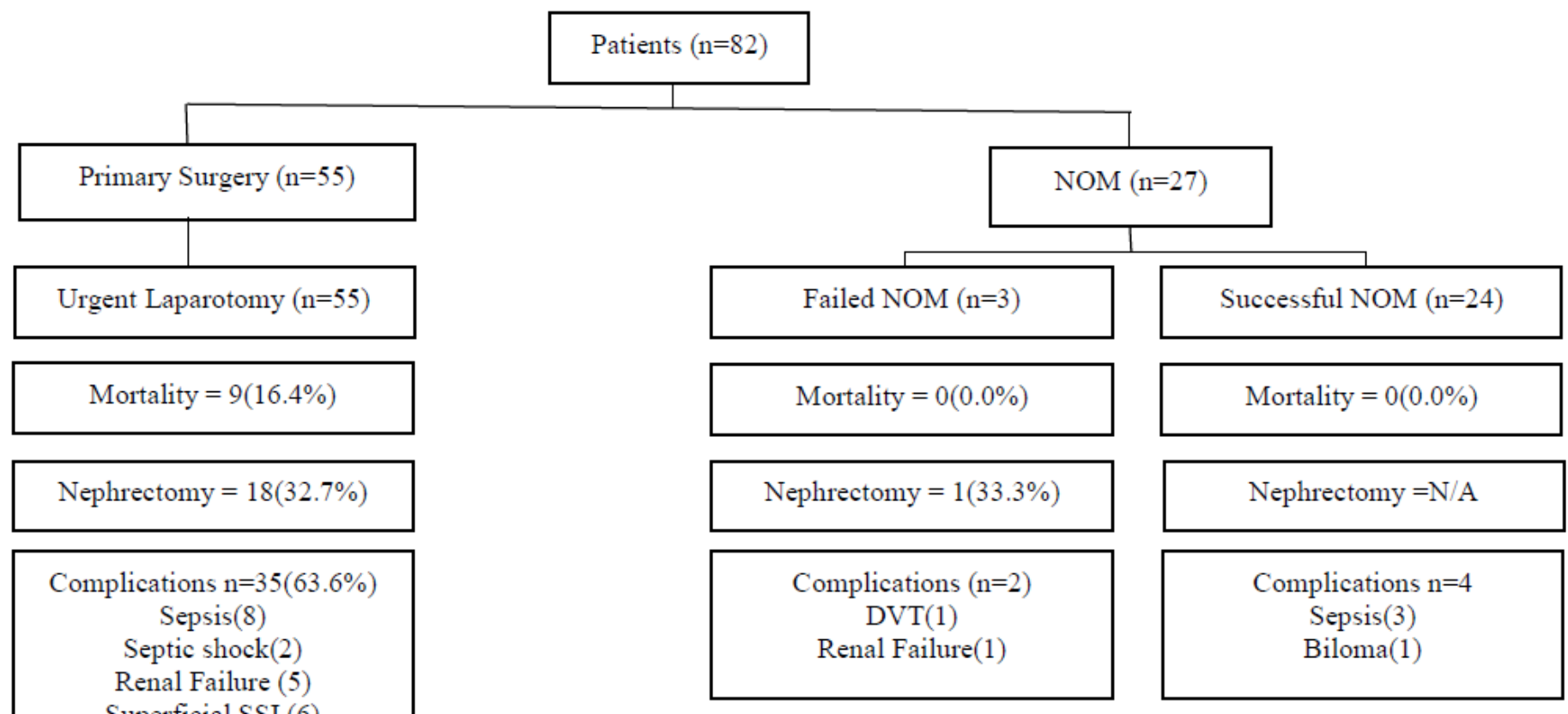

\section{Figure 3}

Clinical decision pathways and outcomes for patients sustaining abdominal gunshot wounds causing renal injuries. NOM = Non-operative management. Failure of NOM was defined as a need for laparotomy. Successful NOM patients were managed without the need for surgical intervention. Primary surgery is defined as the need for emergent/urgent laparotomy directly from the emergency department prior to admission to a hospital ward/intensive care unit. 